Supporting Information for

\title{
Crystallization and Rheology of Poly(ethylene oxide) in Imidazolium
}

\section{Ionic Liquids}

Fuyong Liu, ${ }^{\dagger, \downarrow}$ Yuxia Lv, ${ }^{\dagger, \$}$ Jiajian Liu, ${ }^{\dagger, \star}$ Zhi-Chao Yan, ${ }^{\dagger, \star}$ Baoqing Zhang, ${ }^{\dagger}$ Jun Zhang, ${ }^{*,+, *}$ Jiasong He, ${ }^{\dagger}$ and Chen-Yang Liu ${ }^{*,+\star}$

${ }^{\dagger}$ Beijing National Laboratory for Molecular Sciences, CAS Key Laboratory of Engineering Plastics, Institute of Chemistry, the Chinese Academy of Sciences, Beijing 100190, China

${ }^{*}$ University of Chinese Academy of Sciences, Beijing, 100049, China

$\S$ Institute of Environmental Science, Shanxi University, Taiyuan 030006, China.

\section{Table of Contents}

1. Melting Points as a Function of PEO Weight Fraction in Different ILs ............................ 2

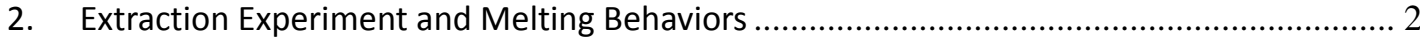

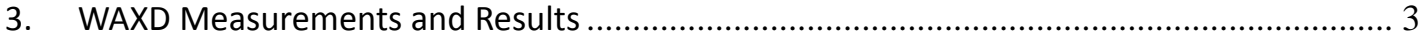

4. Hoffman-Weeks Plots and Equilibrium Melting Points............................................... 4

5. Melting Curves of Extracted PEO in Different ILs............................................................ 5

6. Stability of PEO During the Solution Preparation and the Rheological Measurements ........ 6

7. Effect of Temperature on the Rheological Behaviors of PEO/ILs Solutions ......................... 8

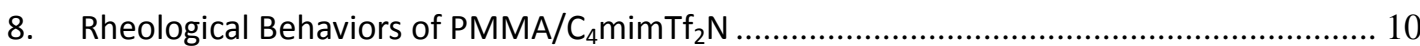

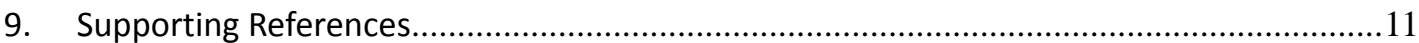




\section{Melting Points as a Function of PEO Weight Fraction in Different ILs}

Melting points of mixtures with various PEO fraction in different ILs were measured by differential scanning calorimetry (DSC) instrument (TA Instruments Q20). Hermetically sealed sample was heated to $80^{\circ} \mathrm{C}$ and held for 10 min erasing thermal history. Then, the temperature was quenched to $0{ }^{\circ} \mathrm{C}$ to get well crystalized sample. After that, a heating scan at $5{ }^{\circ} \mathrm{C} / \mathrm{min}$ was launched and the curve was recorded. DSC software (TA Universal Analysis 2000) was employed to analyze the thermogram, with the melting temperature identified as the position of the endothermic minimum. Melting points of PEO in different ILs as a function of PEO fraction is shown in Figure S1. It is clear that, melting points of PEO in different ILS as a function of PEO fraction show the similar trend, decrease with decreasing PEO fraction.

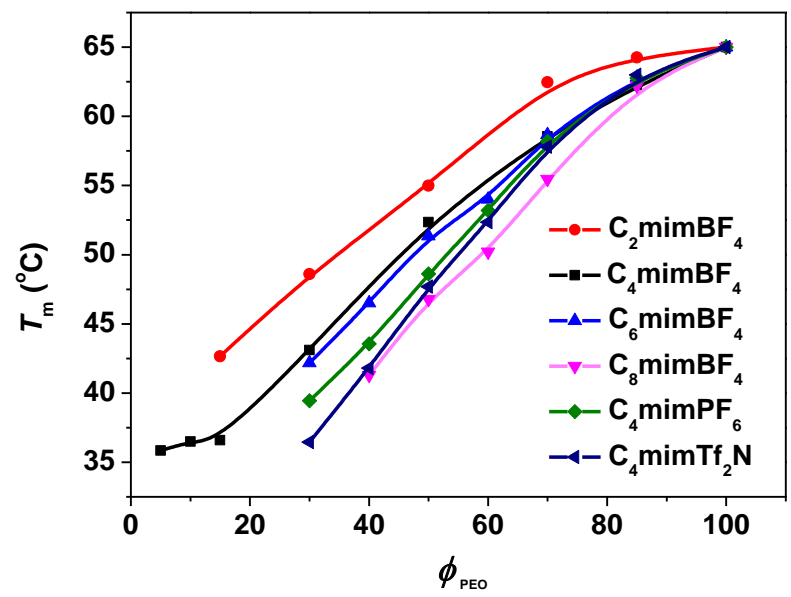

Figure S1. Melting points as a function of PEO weight fraction in different ILs

\section{Extraction Experiment and Melting Behaviors}

Solutions made at $100{ }^{\circ} \mathrm{C}$ with concentration of $10 \mathrm{wt} \%$ and $30 \mathrm{wt} \%$ PEO $\left(M_{\mathrm{w}}=20\right.$ $\mathrm{kg} / \mathrm{mol}$, Sigma Aldrich) in $\mathrm{C}_{4} \mathrm{mimBF}_{4}$ were well crystalized at room temperature to get the mixtures of PEO crystal in $\mathrm{C}_{4} \mathrm{mimBF}_{4}$. Crystallized $\mathrm{PEO} / \mathrm{C}_{4} \mathrm{mimBF}_{4}$ mixture $(10$ wt \% or 30 wt \% PEO-20k) was soaked in enough acetone and stirred at room temperature followed by suction filtration. The filter cake was washed 3 times by using acetone to remove residual $\mathrm{C}_{4} \mathrm{mimBF}_{4}$. Finally, the filter cake was dried under vacuum for at least $24 \mathrm{~h}$ at room temperature. This sample is called as extracted PEO. 
The melting behaviors of extracted PEO, crystalized PEO/ $\mathrm{C}_{4} \mathrm{mimBF}_{4}$ mixture (PEO mass fraction of $30 w t \%)$, and pure PEO were measured using DSC. The results are shown in Figure S2. It is clear that the extracted PEO crystals have the same melting curve as that of pure PEO, demonstrating that $\mathrm{C}_{4} \mathrm{mimBF}_{4}$ can be completely removed from $\mathrm{PEO} / \mathrm{C}_{4} \mathrm{mimBF}_{4}$ mixture, PEO and ILs do not co-crystallize.

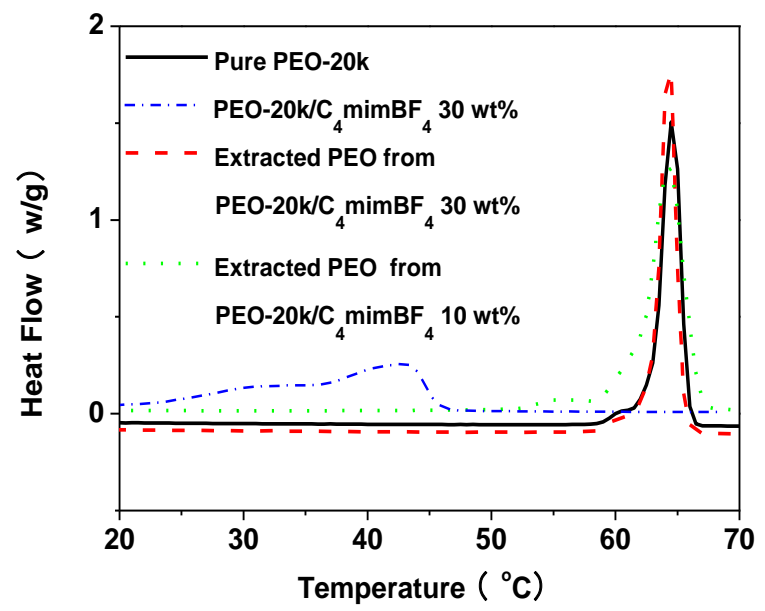

Figure S2. The DSC melting curves for different samples. The heating rate was $5{ }^{\circ} \mathrm{C} / \mathrm{min}$.

\section{WAXD Measurements and Results}

Solutions of $\mathrm{PEO} / \mathrm{C}_{4} \mathrm{mimBF}_{4}$ (30 wt \%) prepared at $100{ }^{\circ} \mathrm{C}$ was well crystalized at room temperature. The sample of pure PEO was compression molded into the film using a hot press at $90{ }^{\circ} \mathrm{C}$. Dried filter cake (extracted PEO crystals) was made as described in supporting section 2 . The diffraction pattern of the three samples were obtained with a Ragaku D/max-2500 diffractometer using Ni-filtered Cu-Ka radiation $(\lambda=0.1542 \mathrm{~nm}, 40 \mathrm{kV}$, $200 \mathrm{~mA}$ ). Measurements were performed over the range $2 \theta$ from $5^{\circ}$ to $40^{\circ}$ at a scanning rate of $5 \% \mathrm{~min}$.

WAXD for pure PEO, crystalized PEO/C $\mathrm{CmimBF}_{4}$ (30 wt \%) and extracted PEO were compared in Figure S3. The three samples have identical diffraction peaks, corresponding to the usual monoclinic PEO unit cell; main peaks are assigned to the (120) and (032) planes of packed 7:2 helices. $\mathrm{C}_{4} \mathrm{mimBF}_{4}$ thus does not alter crystal chain packing, and most likely, the polymer and solvent do not co-crystallize. 


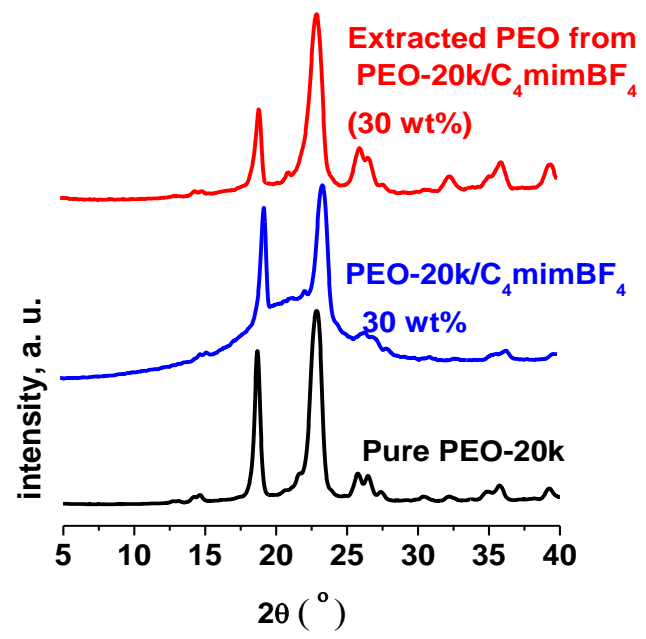

Figure S3. WAXD of pure PEO-20k, PEO-20k/ $\mathrm{C}_{4} \mathrm{mimBF}_{4}$ (30 wt\%) and extracted PEO from PEO-20k/ $\mathrm{C}_{4} \mathrm{mimBF}_{4}$ (30 wt\%).

\section{Hoffman-Weeks Plots and Equilibrium Melting Points}

The solutions of PEO in different ILs made at $100{ }^{\circ} \mathrm{C}$ with various PEO concentration were hermetically sealed within an aluminum pan and placed in the differential scanning calorimetry (DSC) instrument. Hermetically sealed samples were heated to $80^{\circ} \mathrm{C}$ and held for $10 \mathrm{~min}$ erasing thermal history. After a quench to appointed temperature, the sample was held for enough time to get well crystalized sample before the recording of a heating scan at $5{ }^{\circ} \mathrm{C} / \mathrm{min}$. The melting temperature $\left(T_{\mathrm{m}}\right)$ identified as the position of the endothermic minimum. $T_{\mathrm{m}}$ of PEO/ILs samples were plotted as a function of crystallization temperature $\left(T_{c}\right)$ according to the method described by Hoffman and Weeks ${ }^{1}$. Figure S4a displays the Hoffman-Weeks plots to obtain the equilibrium melting temperatures of pure $\mathrm{PEO}$ and the PEO component in various PEO/C ${ }_{4} \mathrm{mimBF}_{4}$ blends.

Figure S4b shows the equilibrium melting temperature of the PEO component in different ILs blends, which decrease upon increasing the weight fraction of ILs because of the decrease in the chemical potential resulting from the addition of the second component. The decreasing degree depends on the structures of ILs. 
a)

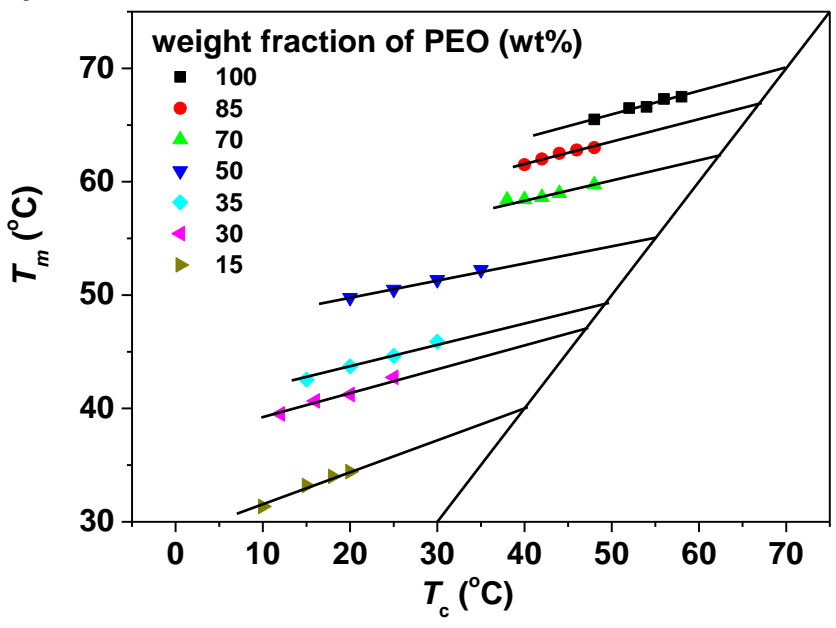

b)

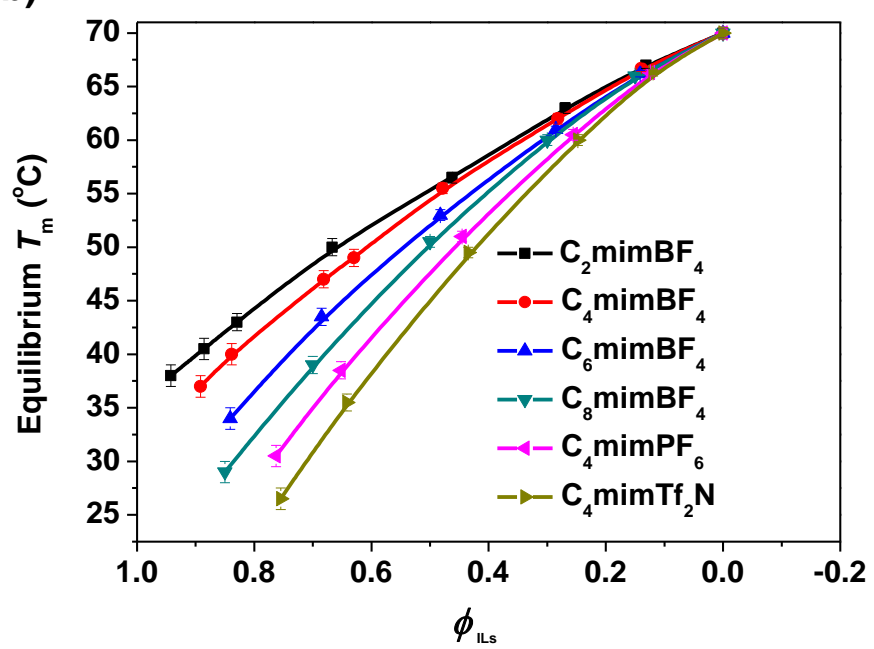

Figure S4. (a) Hoffman-Weeks plot for isothermally crystallized PEO and blends with $\mathrm{C}_{4} \mathrm{mimBF}_{4}$. (b) The equilibrium melting point of PEO-20k in ILs with different alkyl length of cations and different kinds of anions.

\section{Melting Curves of Extracted PEO in Different ILs}

The extracted PEO was dipped into different ILs to form mixtures (10 wt\% PEO), and then put into vacuum oven for 12 hours at room temperature to remove air bubbles and make the PEO crystal surface contact with ILs sufficiently. This sample is called as remixed PEO/ILs. Melting behaviors of these remixed PEO/ILs samples were measured using DSC at $5^{\circ} \mathrm{C} / \mathrm{min}$.

The melting curves shown in Figure $\mathrm{S} 5$ reveal that $T_{\mathrm{m}}$ of extracted PEO in different ILS decreases with increasing the length of alkyl of imidazolium cation (Figure S5a), and also 
decreases with anions as the following sequence, $\mathrm{BF}_{4}^{-}>\mathrm{PF}_{6}^{-}>\mathrm{Tf}_{2} \mathrm{~N}^{-}$(Figure $\mathrm{S} 5 \mathrm{~b}$ ).

a)

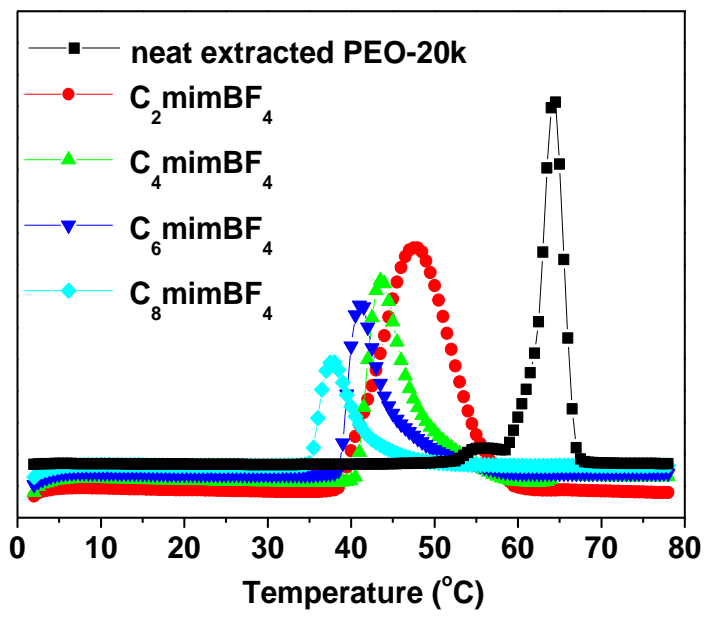

b)

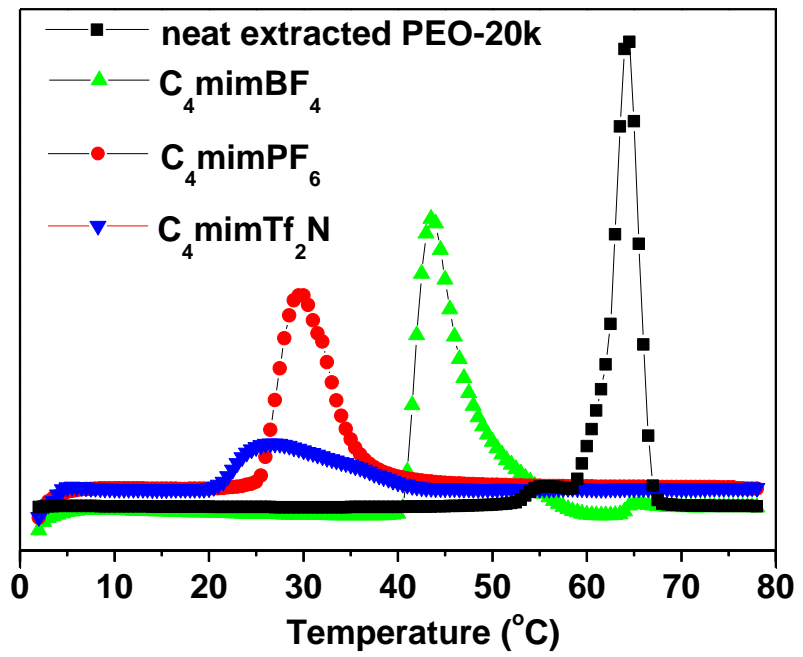

Figure S5. The DSC melting curves of extracted PEO-20k dipped in ILs (a) with different alkyl length, (b) with different anions. The size of peaks does not represent the actual melting enthalpy and the DSC curves are just used to read the melting point.

\section{Stability of PEO during the Solution Preparation and the Rheological Measurements}

First, PEO-1M solutions with a concentration of $0.04 \mathrm{~g} / \mathrm{ml}$ (the highest concentration in Figs. 4a and $4 b$ ) were prepared by two different methods. The dissolution procedure with ultrasound and stirring was used in the paper. The control procedure without ultrasound was used, and it takes about 14 hours (only with few very gentle stirring) to completely dissolve PEO-1M in water or in ionic liquids. Steady shear test were made with 
shear rate increasing from 0.01 to $100 \mathrm{~s}^{-1}$.

Figures S6a and S6b below show the steady shear viscosity curves for PEO-1M/ $\mathrm{H}_{2} \mathrm{O}$ and $\mathrm{PEO}-1 \mathrm{M} / \mathrm{C}_{4}$ mimPF$_{6}$. The difference between the zero-shear viscosities of samples obtained by two dissolution methods is less than $5 \%$. These tests indicated the ultrasound and stirring during the dissolution procedure cannot induce an obvious degradation of PEO.
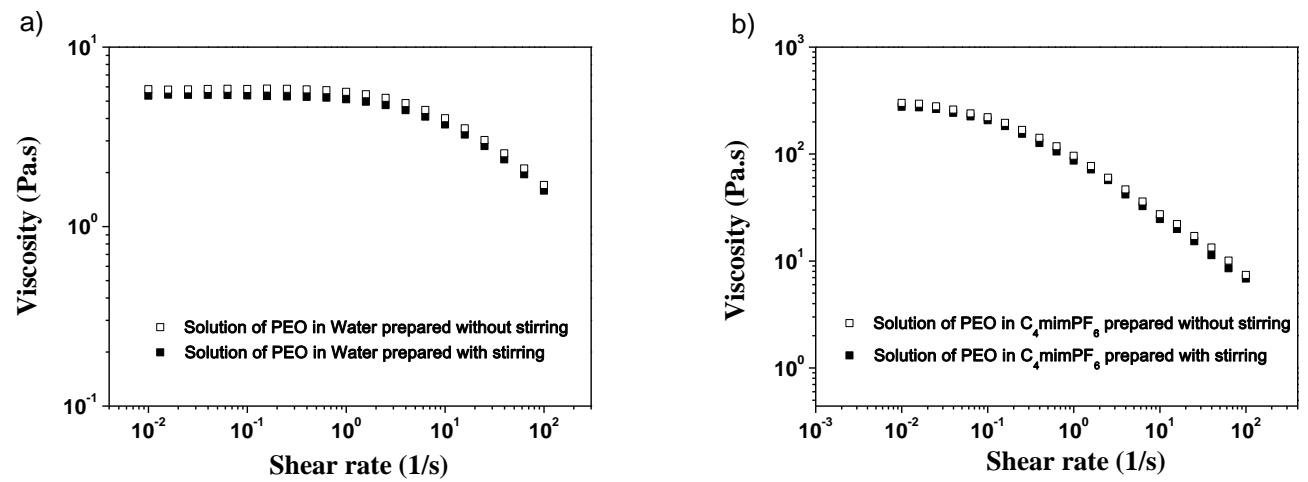

Figure S6. The steady shear curves of (a) Solution of PEO-1M/ $\mathrm{H}_{2} \mathrm{O}$ with concentration of $0.04 \mathrm{~g} / \mathrm{ml}$ (b) Solution of PEO- $1 \mathrm{M} / \mathrm{C}_{4} \mathrm{mimPF}_{6}$ with concentration of $0.04 \mathrm{~g} / \mathrm{ml}$. Comparison the influence of different dissolution procedures.

a)

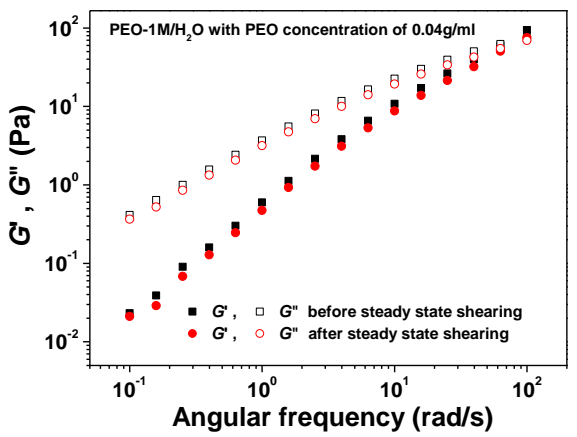

b)

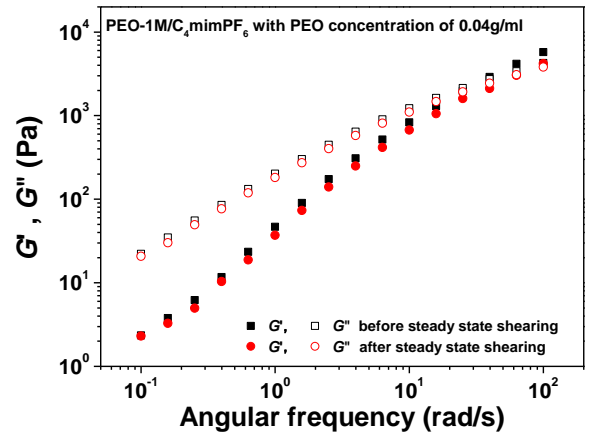

Figure S7. Dynamic frequency sweep for (a) PEO- $1 \mathrm{M} / \mathrm{H}_{2} \mathrm{O}(0.04 \mathrm{~g} / \mathrm{ml})$ and (b) PEO- $1 \mathrm{M} / \mathrm{C}_{4} \mathrm{mimPF}_{6}(0.04 \mathrm{~g} / \mathrm{ml})$ before and after steady-state shear test. Rheological tests were carried out at $25^{\circ} \mathrm{C}$ with $20 \mathrm{~mm}$ parallel-plate.

Second, before and after the steady shear test, the dynamic frequency sweeps were performed to monitor chain degradation induced by shear. Slight decreases of G' and G" were observed in Figures S7a and S7b. However, we also observed that a small amount samples were thrown out the fixture, which may lead to the decrease of $\mathrm{G}^{\prime}$ and $\mathrm{G}^{\prime \prime}$. 


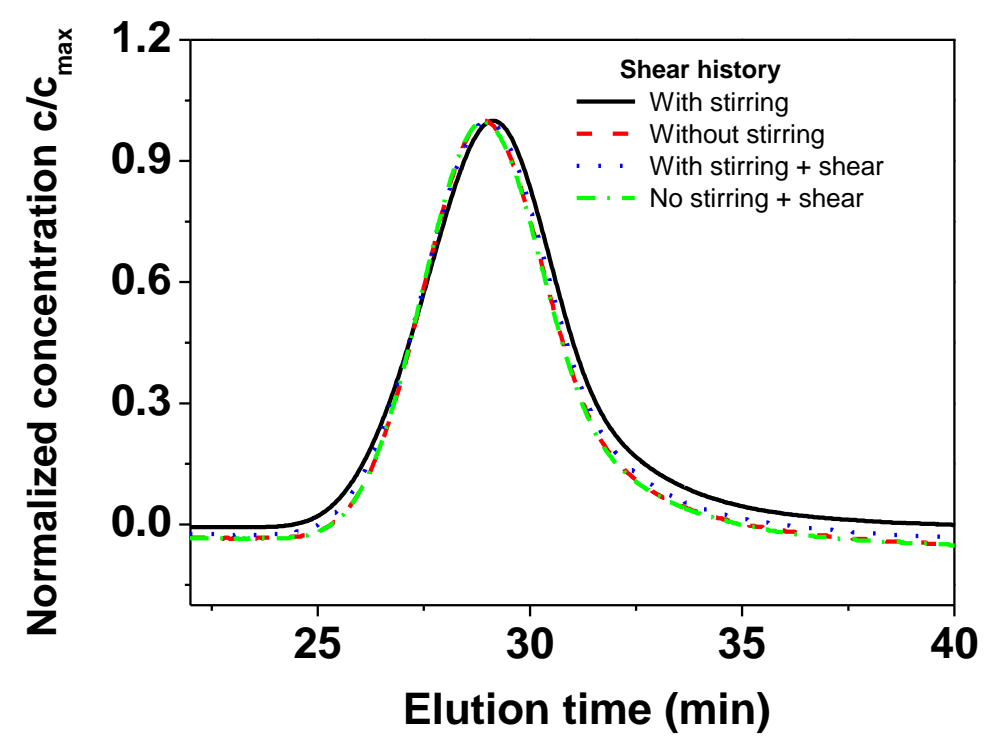

Figure S8. GPC chromatogram of PEO samples with different shear histories.

Last, for PEO-1M solutions $(0.04 \mathrm{~g} / \mathrm{ml})$, GPC test were carried out for samples prepared by two different methods (with or without strong stirring). In addition, the samples after the steady shear test were also checked by GPC. Figure $\mathrm{S} 8$ shows that there no obvious change among four samples with different shear histories.

Above tests proved that PEO has a good stability in this study.

\section{Effect of Temperature on the Rheological Behaviors of PEO/ILs Solutions}

Steady shear viscosity measurements have been performed on $\mathrm{PEO} / \mathrm{C}_{4} \mathrm{mimPF}_{6}$ and PEO $/ \mathrm{C}_{4}$ mimTf ${ }_{2} \mathrm{~N}$ solutions at $25{ }^{\circ} \mathrm{C}$ and $80{ }^{\circ} \mathrm{C}$, respectively. Zero-shear viscosity $(\eta)$ were obtained from the apparent viscosity curves, and then the specific viscosity at $25{ }^{\circ} \mathrm{C}$ and $80{ }^{\circ} \mathrm{C}$, were plotted as a function of PEO concentration in Figure S9a (for PEO/ $\mathrm{C}_{4} \mathrm{mimPF}_{6}$ ) and Figure S9b (for PEO/ ${ }_{4}$ mimTf $_{2} \mathrm{~N}$ ) in double logarithm form. It is clear that, the value of $\eta_{\mathrm{sp}}$ and the scaling laws of $\eta_{\mathrm{sp}}$ against concentration are very similar at $25^{\circ} \mathrm{C}$ and $80^{\circ} \mathrm{C}$. It implies that for ILs, as a solvent composed of cation and anion, their solvent quality are insensitive to temperature within this range $\left(25-80^{\circ} \mathrm{C}\right)$.

Steady state flow tests were also launched on the two systems with various PEO molecular weight at $25^{\circ} \mathrm{C}$ and $80^{\circ} \mathrm{C}$. A plot of $\eta_{\text {sp }} / c$ as a function of concentration produces a straight line with the intercept equal to $[\eta]$ as described by Huggins equation ${ }^{2}$ : 
$\eta_{\mathrm{sp}} / c=[\eta]+k_{\mathrm{H}}[\eta]^{2} c$.

Molecular weight dependence of $[\eta]$ at 25 and $80{ }^{\circ} \mathrm{C}$ were compared in Figure S9c, which shows that there is little difference for $\alpha$ value at two temperatures. Therefore, we can safely compare four groups of data at different temperatures.

a)

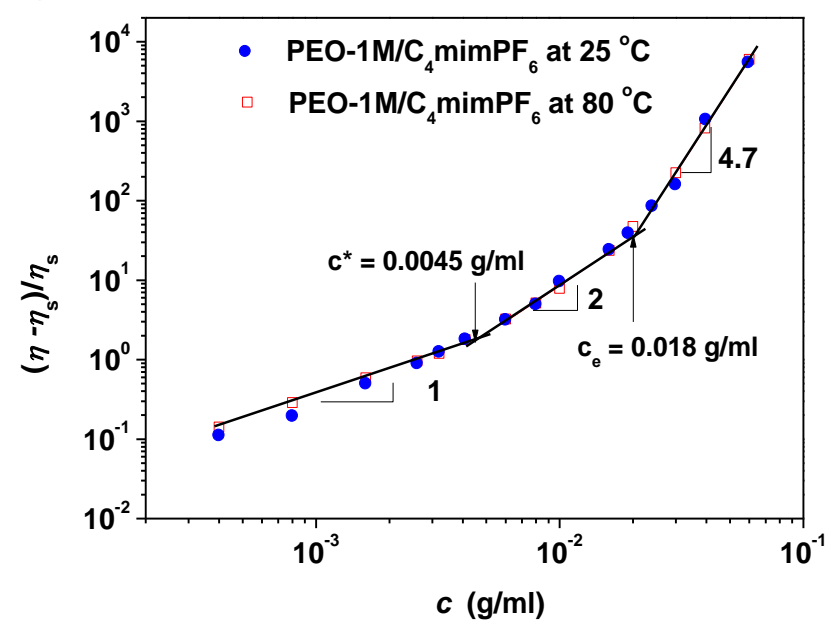

b)

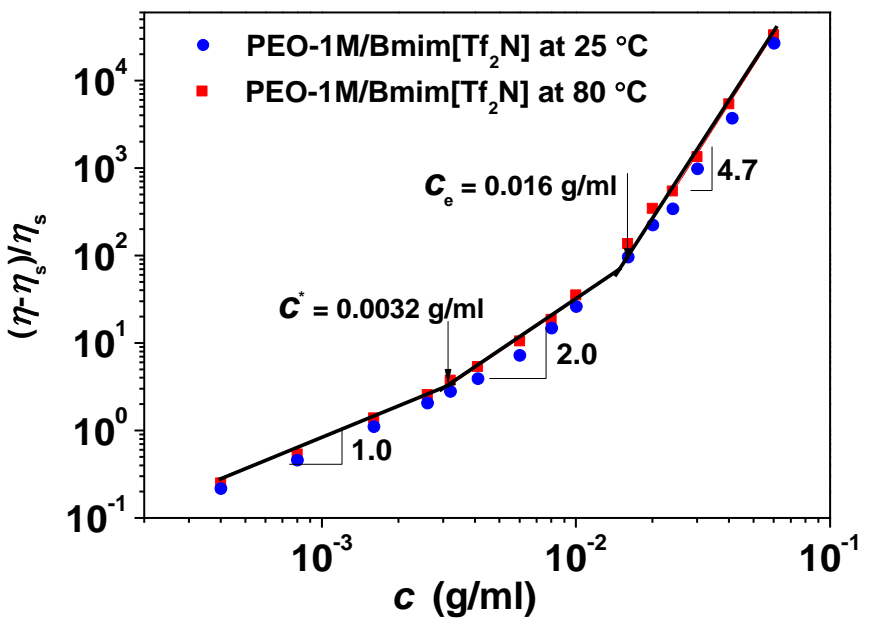




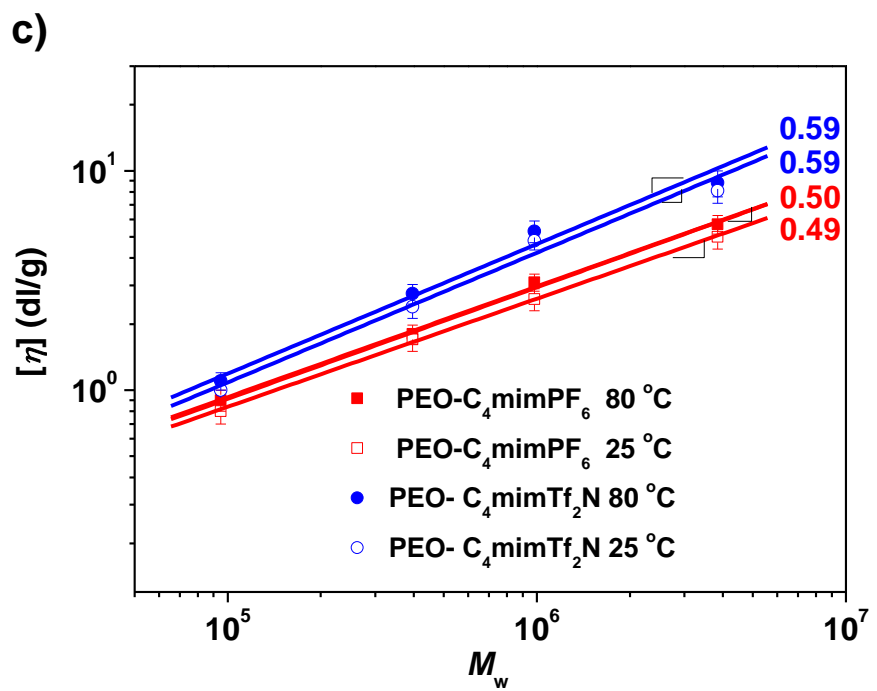

Figure 59. Concentration dependence of specific viscosity $\left(\eta_{\mathrm{sp}}\right)$ for (a) $\mathrm{PEO} / \mathrm{C}_{4} \mathrm{mimPF}_{6}$ solutions at 25 and $80{ }^{\circ} \mathrm{C}$, (b) PEO/C ${ }_{4} \operatorname{mimTf}_{2} \mathrm{~N}$ solutions at 25 and $80{ }^{\circ} \mathrm{C}$. (c) Molecular weight dependence of intrinsic viscosity $([\eta])$ for PEO inC $_{4}$ mimPF $_{6}$ and $\mathrm{C}_{4} \mathrm{mimTf}_{2} \mathrm{~N}$ at 25 and $80^{\circ} \mathrm{C}$.

\section{Rheological Behaviors of $P M M A / C_{4} m i m T f_{2} N$}

Steady shear viscosity measurements have been performed on $\mathrm{PEO} / \mathrm{C}_{4} \mathrm{mimTf}_{2} \mathrm{~N}$ solutions. Figure S10a shows the apparent viscosity curves for PEO/ $\mathrm{C}_{4} \operatorname{mimTf} \mathrm{f}_{2} \mathrm{~N}$ at $25^{\circ} \mathrm{C}$. Zero-shear viscosity $(\eta)$ were obtained from the apparent viscosity curves, and then the specific viscosity at $25^{\circ} \mathrm{C}$ and $80{ }^{\circ} \mathrm{C}$, were plotted as a function of PEO concentration in Figure $\mathrm{S} 10 \mathrm{~b}$ in double logarithm form. It looks apparently that $\mathrm{PMMA} / \mathrm{C}_{4} \mathrm{mimTf_{2 }} \mathrm{N}$ shows the same scaling laws of concentration dependence of $\eta_{\text {sp }}$ as $P E O / C_{4}$ mimTf $_{2} \mathrm{~N}$ system in three concentration regimes, consistent with the theoretical predication of neutral polymer in theta solvent solutions. The temperature has also little influence on the rheological behaviors of $\mathrm{PMMA} / \mathrm{C}_{4} \mathrm{mimTf}_{2} \mathrm{~N}$ solutions. 


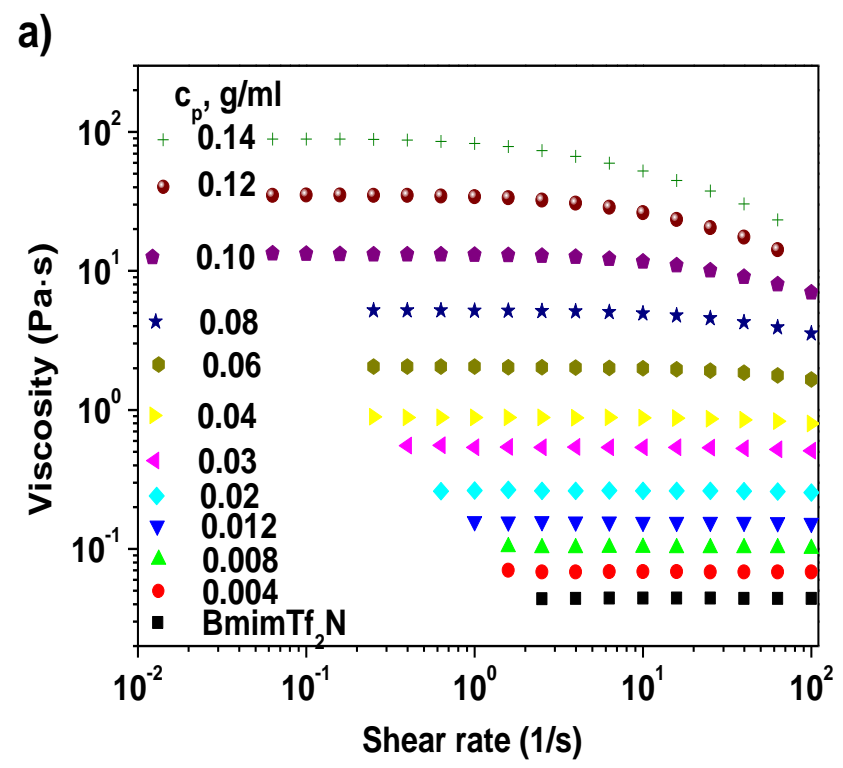

b)

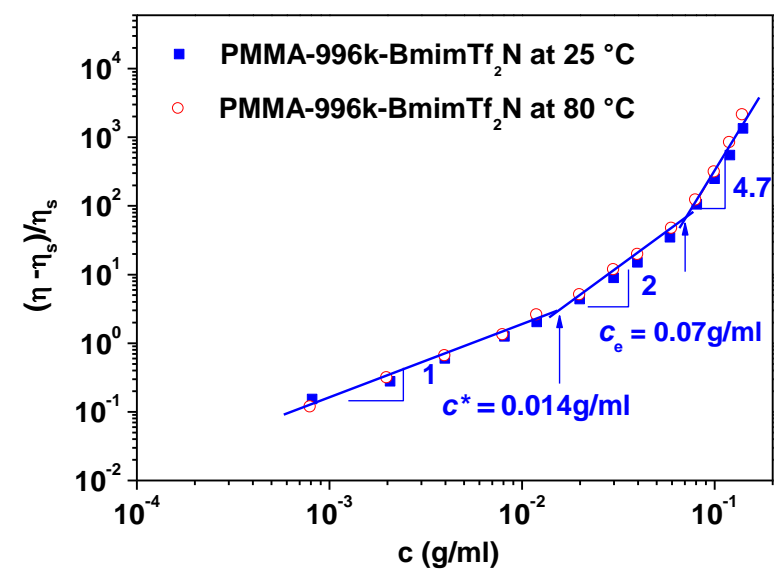

Figure S10. (a) The steady shear profiles of $\mathrm{PMMA} / \mathrm{C}_{4} \operatorname{mimTf}_{2} \mathrm{~N}$ at $25^{\circ} \mathrm{C}$. (b) Concentration dependence of specific viscosity $\left(\eta_{\text {sp }}\right)$ for $\mathrm{PMMA} \mathrm{C}_{4} \operatorname{mimTf}_{2} \mathrm{~N}$ solutions at 25 and $80^{\circ} \mathrm{C}$.

\section{Supporting References}

1. Hoffman, J. D.; Weeks, J. J. J. Chem. Phys. 1965, 42, 4301.

2. Rubinstein, M.; Colby, R. H. Polymer Physics. Oxford University Press, USA: 2003. 